\title{
Effects of acidic fertilizers spray on the improvement of iron chlorosis in grape cv. Askari in Yasouj
}

\author{
Jahanshir Ahmadi $^{\text {** }}$, Aslanpour Mohammad (Mohammad Omar Aziz) ${ }^{2}$ and Mohammad Reza \\ chakeralhosseini $^{3}$ \\ ${ }^{1}$ Horticulture Crops Research Department, Kohgiluyeh and Boyerahmad Agricultural and Natural \\ Resources Research and Education Center, AREEO, Yasouj, Iran \\ ${ }^{2}$ Associate Professor of Department of Horticulture University of Raparin Rania, Sulaimany, Kurdistan, Iraq \\ ${ }^{3}$ Soil and water Research Department, Kohgiluyeh and Boyerahmad Agricultural and Natural \\ Resources Research and Education Center, AREEO, Yasouj, Iran \\ email address: ana_ahmadi2005@yahoo.com*
}

\begin{abstract}
Askari grape is one of the dominant cultivars of southwest of Iran and is one of the main income sources of the people of the region, which is used as fresh, grape juice, sap and raisin. Lime rate over $60 \%$ in soil is one of the main problems in the vineyards of the region. High amount of lime causes an increase in the chlorophyll content of grape leaves and reduction in the quality and quantity of grapes. Iron deficiency is one of the major problems in calcareous soils. In order to reduce leaf chlorosis and increase the quantitative and qualitative characteristics of grape, the present research was carried out in a randomized complete block design with three replications in southwest of Iran for two years. Treatments consisted of citric acid $2000 \mathrm{mg} / \mathrm{L}$, citric acid $6000 \mathrm{mg} / \mathrm{L}$, sulfuric acid $38 \mathrm{mg} / \mathrm{L}$, iron sulfate $5000 \mathrm{mg} / \mathrm{L}$ and distilled water as control were applied as spraying method. The results of compound analysis of variance of yield, cluster length, cluster weight and percentage of soluble solids (TSS) showed that the effects of fertilizer treatments as well as the interaction between year and fertilizer treatments on these characteristics were not significant, but means comparison showed that the application of all fertilizer treatments caused an improvement in these characteristics in comparison with control. Effects of fertilizer treatments and the interaction of year and fertilizer treatments on leaf iron content were significant at 1 and 5\% probability levels, respectively. Means comparison of iron concentration in grape leaf showed that iron sulfate spray at concentration of $5000 \mathrm{mg} / \mathrm{L}$ significantly increased iron concentration in grape leaves compared to control and other treatments.
\end{abstract}

Key words: Chlorosis, grape, Citric acid, Sulfuric acid, Iron sulfate

\section{Introduction:}

Although there is high potential in southwest of Iran for cultivating and developing irrigated and rainfed grape orchards, unfortunately the average yield of grape and its desired quality are far below the global average that can be due to imbalanced consumption of fertilizers or the factors that make the elements essential unavailable in the plant, for example iron (Chakeralhosseini, 2000). Reduction of iron absorption or its unavailability in plant leads to iron chlorosis, resulting in a decrease in photosynthesis and yield. In calcareous soils of southwest of Iran, high $\mathrm{pH}$, lime, and abundant carbonate and bicarbonate in water reduce the absorption of microelements, or cause these elements to become unavailable in plant tissue (Salardini, 2009). High indence of Fe deficiency in human population caused that increasing Fe concentration in food crops be an important global challenge (Pfeiffer and McClafferty, 2007; Borg et al., 2009).

Due to the high $\mathrm{pH}$ of soil and abundance of calcium carbonate in orchards and farms of southwest of Iran, there is a probability of inappropriate nutrition of microelements. In different sources, leaf yellowing caused by iron deficiency in calcareous soils has been attributed to the type of nitrogen nutrition. The type of nitrogen fertilizer can cause the $\mathrm{OH}^{-}$and $\mathrm{H}^{+}$ions to be secreted, affecting the $\mathrm{pH}$ of leaf apoplast and preventing iron adsorption (Malakouti and Tabatabaei, 1999).

Generally, the degree of yellowing in leaves of plants grown in calcareous soils does not correspond to the concentration of leaf iron, so that it may be even higher than that in green leaves. This fact proposes a hypothesis that bicarbonate is the most important factor slowing down iron in calcareous soils and makes iron immobile in plant tissues (Mengel et al., 1984). The presence of bicarbonate in environment increases the $\mathrm{pH}$ of the cytoplasm of the plants, and the increase in the $\mathrm{pH}$ of leaf apoplast by bicarbonate causes iron to be precipitated as hydroxide and phosphate before passing through the plasma membrane or it reduces the activity of iron reductase (Kolesch et al., 1987). On the other hand, increasing the $\mathrm{pH}$ of leaf apoplast causes the precipitation or inactivation of the elements that are absorbable at low $\mathrm{pH}$, thus the enzymes that are activated 
by these elements are also inactivated, and a fact that leads to the reduction of photosynthesis and yield (Bienfait and Scheffers, 1992; Brown, 1961).

Furthermore, the results of another study that was carried out to determine the nutritional disorders of grapes in the same station showed that iron deficiency symptoms (inactivation of iron in the leaf despite the presence of enough iron around $230 \mathrm{mg} / \mathrm{kg}$ in leaf) exist in $56 \%$ of the orchards with low yield due to high lime of soil up to $60 \%$ and high $\mathrm{pH}$ (Godarzi, 1999). It has been reported in various sources that the use of nitrate fertilizers increases the apoplast $\mathrm{pH}$ of leaves and converts iron into unavailable form, and as a result, leaf yellowing has been reported to be caused by nitrate fertilizers (Cain, 1952; Colgrove and Roberts, 1956; Kirkby and Mengel, 1967; Machold, 1967; Mengel and Mallasov, 1982; Mengal and Geurtzen, 1988; Van den Driessche, 1978).

The use of nitrate fertilizers causes an increase in $\mathrm{OH}^{-}$ion and consequently in the $\mathrm{pH}$ of leaf apoplast, thus producing chlorosis. On the other hand, the use of ammonium fertilizers, by increasing the $\mathrm{H}^{+}$ion and decreasing the $\mathrm{pH}$ of leaf apoplast, prevents the stabilization of iron in unavailable form and thus prevents the production of chlorosis (Mengel et al., 1984). It has been reported in some studies that iron concentrations in chlorotic leaves may be even higher than those in green leaves, and its cause has been reported to be high $\mathrm{pH}$ of leaf apoplast, which causes iron to be fixed and prevents the transport of iron from apoplast to leaf symplast (Carter, 1980 and Van den Driessche, 1978). It was also reported that iron concentration in chlorotic leaves of Soybean-203 was higher than that in green leaves of Hawkeye (Bienfait and Scheffers, 1992). Nitrate increases the $\mathrm{pH}$ of leaf apoplast and reduces the transport of $\mathrm{Fe}$ from apoplast to symplast (Mengel and Malissiovas, 1982). It has also been suggested that nutrition with ammonium fertilizers reduces the $\mathrm{pH}$ of leaf apoplast, activates the plasma proton pump and increases the transport of iron from apoplast to symplast. High level of bicarbonate in irrigation water is one of the causes of iron chlorosis, especially in calcareous soils with poor ventilation. Moreover, high nitrogen nutrition, especially when the nitrogen supply source is nitrate, is another cause of chlorosis. Various sources emphasize that bicarbonate and nitrate intensify iron chlorosis (Mengal et al., 1994). The results of a study showed that spraying with indole acetic acid and fusicoccin led to the regreening of chlorotic leaves of corn. Considering that both above-mentioned chemicals activate the plasma proton pump and thus the transport of $\mathrm{H}^{+}{ }_{1}$ ion into the symplast increases, it is suggested that the $\mathrm{pH}$ of apoplast in some cases correlates with iron chlorosis, and nitrate nutrition and the presence of bicarbonate increase the $\mathrm{pH}$ of leaf apoplast and slow down the transport of iron from apoplast to the symplast (Mengal et al., 1994). Iron is reported to be transported as a citrate complex from root to leaf, and low PH ensures the stability of this complex (Tagliavini et al., 1995). Other reports suggest that in low $\mathrm{pH}$, iron is reduced and transported into cell, an action which intensifies the formation of chlorophyll (Brown, 1961; Tagliavini et al., 1995). Reducing the $\mathrm{pH}$ of leaf apoplast as a result of citric acid spray increases the transport of iron from apoplast to leaf symplast and reduces chlorosis resulting from iron deficiency in leaves (Mengal and Geurtzen, 1988; Tagliavini et al., 1995).

Since the use of high amounts of iron is effective in preventing leaf yellowing, much of the iron used in plants is in unavailable and non-transportable form, which cannot be used in the physiological stages of the plant (Chen and Barak, 1982; Mengel et al., 1984; Tagliavini et al., 1993). In pea plant, spray of sulfuric acid $0.1 \%$ and iron $0.2 \%$ caused $33.47 \%$ and $29.92 \%$ increases in chlorophyll content of leaves, respectively (Sahu et al., 1987). Bicarbonate is reported to be the most important factor producing leaf chlorosis in calcareous soils, and it also converts iron into immobile form in plant tissues (Kolesch et al., 1984; Kolesch et al., 1987; Mengal et al., 1994). Besides, increasing $\mathrm{pH}$ of leaf apoplast by bicarbonate causes the precipitation of iron in the forms of hydroxide and phosphate before passing through the plasma membrane, and reduces the activity of $\mathrm{Fe}$ reductase enzyme (Bienfait and Scheffers, 1992). The re-greening of chlorotic leaves after application of different acidic treatments has been reported (Tagliavini et al., 1993). Also Jozedaemi, et al., (2014) reported that the treatment of sulphoric acid application in irrigation water $(4 \mathrm{~g} / \mathrm{L})$ has the higher level of average compared to other treatments of iron. The treatment of sulphoric acid application in irrigation water causes the increase of manganese, zinc and copper of the leaves in the spotted bean types. The formation of chlorophyll in sunflower leaves grown on calcareous soils by acid spraying has been observed (Mengal and Geurtzen, 1988). According to the results of studies carried out in the region to prevent the reduction of yield caused by leaf chlorosis in vineyards of the region, this experiment was done. Thus, the aim of this study was to identify the efficiency of different $\mathrm{Fe}$ foliar spray to correct Fe deficiency chlorosis in grape grown in calcareous soil.

\section{Materials and methods:}

This experiment was carried out during two years in one of the vineyards of southwest of Iran. Operations including winter pruning and summer pruning, soil nutrition based on soil test and leaf analysis, irrigation and plowing were carried out similarly. The experiment was carried out in a randomized complete block design with four replications and three times of spraying at intervals of ten days, one month after flowering. Treatments included distilled water (control), citric acid $(2000 \mathrm{mg} / \mathrm{L})$, citric acid $(6000 \mathrm{mg} / \mathrm{L})$, sulfuric acid $(38 \mathrm{mg} / \mathrm{L})$ and iron sulfate $(5 \mathrm{mg} / \mathrm{L})$. Three vines were considered for each treatment. Spraying was done at dusk and irrigation was immediately applied. All technical instructions of spraying were taken into account. After application of the treatments, some characteristics including yield, cluster length, cluster weight, leaf iron content and TSS of fruit 
were measured. After collecting the data, compound analysis was performed by MSTAT-C computer software and means comparison was performed using Duncan's multiple range test.

\section{Results}

\subsection{Results in the first year:}

Analysis of variance showed that the applied fertilizer treatments did not have a significant effect on yield, cluster weight and fruit TSS (Table 1). The results related to the analysis of variance of iron concentration in leaf showed that the effect of treatments on this trait was significant $(\mathrm{P} \leq 0.01)$ (Table 1).

Table 1. Results of analysis of variance of yield, weight and length of cluster, leaf iron concentration and soluble solids content (TSS)

\begin{tabular}{ccccccc}
\hline & & \multicolumn{4}{c}{ Mean squares } \\
\cline { 3 - 7 } Sources of variation & DF & Yield & $\begin{array}{c}\text { Cluster } \\
\text { weight }\end{array}$ & $\begin{array}{c}\text { Cluster } \\
\text { length }\end{array}$ & $\begin{array}{c}\text { Iron } \\
\text { concentration }^{\text {ns }}\end{array}$ & TSS \\
\hline Replicate & 3 & $79.33^{\text {ns }}$ & $15749.4^{\text {ns }}$ & $1.172^{\text {ns }}$ & $6985.04^{\text {ns }}$ & $3.07^{\text {ns }}$ \\
Fertilizer treatment & 4 & $22.96^{\text {ns }}$ & $1296.32^{\text {ns }}$ & $2.364^{\text {ns }}$ & $934684.46^{* *}$ & $1.12^{\text {ns }}$ \\
Error & 12 & 25.2 & 1031.86 & 1.968 & 13040.69 & 1.01 \\
\hline Cv $(\%)$ & & 21.49 & 12.7 & 7.80 & 22.08 & 4.86 \\
\hline
\end{tabular}

ns: non significant, *: significant at $\mathrm{p} \leq 0.05, * *$ : significant at $\mathrm{p} \leq 0.01$

Means comparison of iron concentration in leaf showed that iron sulfate at concentration of $5000 \mathrm{mg} / \mathrm{L}$ had the highest effect on leaf iron concentration in comparison with other treatments (Fig. 1). The absorption of elements such as iron in calcareous soils is difficult or, if absorbed by plant, it becomes unavailable for plant. In this experiment, using iron sulfate showed that iron absorption rate in these types of soils was low and, on the other hand, the amount of iron available for the plant in these soils was probably low. The use of iron sulfate as spraying causes acidification of the environment inside plant tissue and increases iron absorption by grape leaves. Grape leaf analysis showed that the amount of leaf iron increased with spraying of iron sulfate. Means comparison showed that iron sulfate treatment by increasing leaf iron concentration by $1380 \mathrm{mg} / \mathrm{kg}$ dry weight of grape leaf was placed in class A and the rest of the treatments were placed in class B. The use of acidic fertilizers in these soils causes a change in the $\mathrm{pH}$ of the plant tissue, so that leaf iron becomes available and leaf chlorosis decreases, thus resulting in an increase in photosynthesis and improvement in qualitative and quantitative characteristics of the berry and fruit juice.

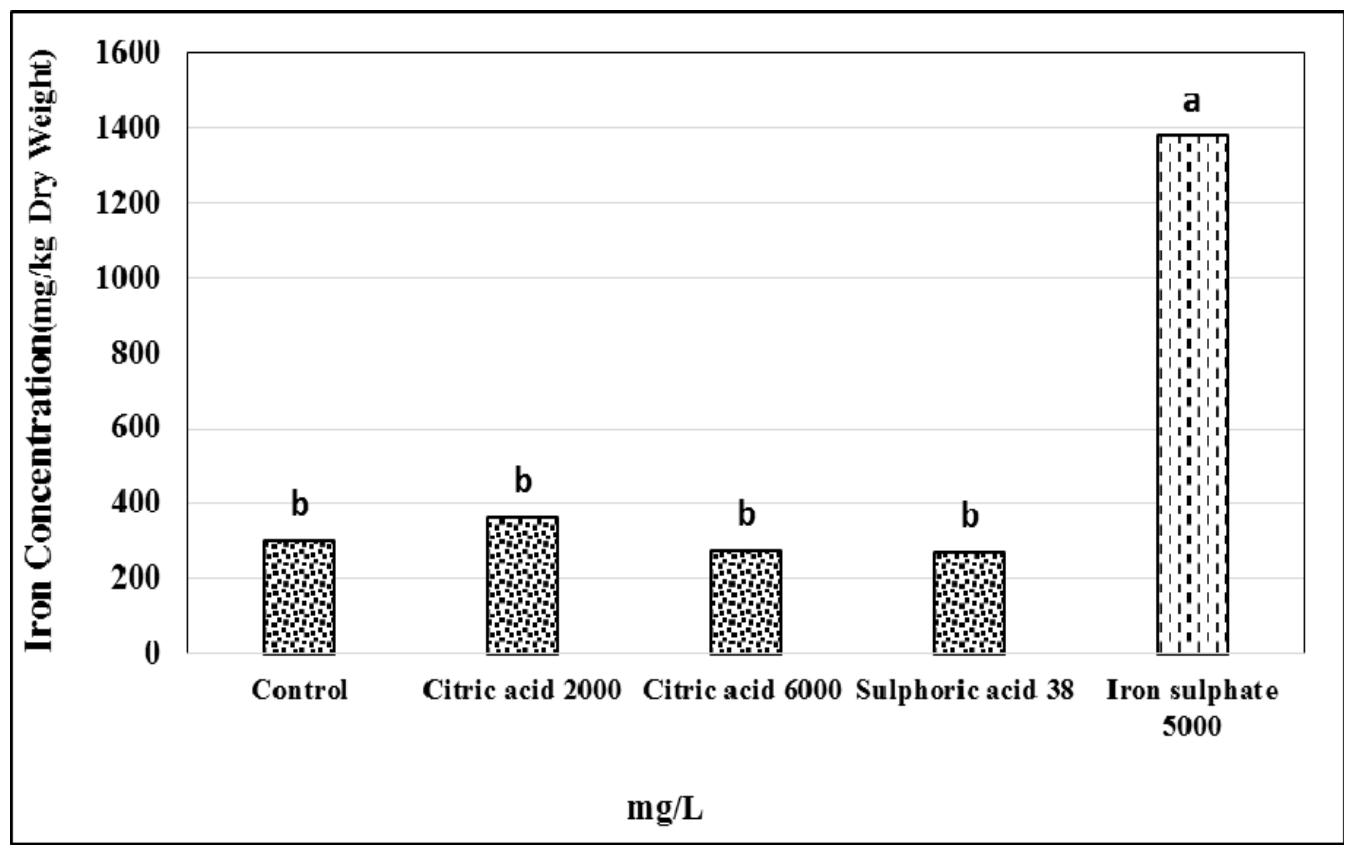

Figure 1. The effect of different treatments on leaf iron concentration in the first year

\subsection{Results in the second year:}

The results obtained from analysis of variance of data for the studied traits [yield, weight and length of cluster, iron concentration and TSS] showed that the treatments did not have a significant effect on these traits like the first year. Analysis of variance of leaf iron concentration showed that the effect of treatments on this trait was significant at $1 \%$ probability level $(\mathrm{P} \leq 0.01)$ (Table 2$)$. 
Table 2. Analysis of variance of yield, weight and length of cluster, iron concentration and percentage of soluble solids (TSS) of fruit

\begin{tabular}{ccccccc}
\hline & & \multicolumn{5}{c}{ Mean squares } \\
\cline { 3 - 7 } $\begin{array}{c}\text { Sources of } \\
\text { variation }\end{array}$ & DF & Yield & $\begin{array}{c}\text { Cluster } \\
\text { weight }\end{array}$ & $\begin{array}{c}\text { Cluster } \\
\text { length }\end{array}$ & $\begin{array}{c}\text { Iron } \\
\text { concentration }\end{array}$ & TSS \\
\hline Replicate & 3 & $27.568^{\text {ns }}$ & $4809.133^{\text {ns }}$ & $5.633^{\text {ns }}$ & $4688.976^{\text {ns }}$ & $3.138^{\text {ns }}$ \\
Fertilizer treatment & 4 & $18.363^{\text {ns }}$ & $4907.175^{\text {ns }}$ & $3.262^{\text {ns }}$ & $516248.128^{* *}$ & $0.593^{\text {ns }}$ \\
Error & 12 & 10.013 & 3079.508 & 10.029 & 5169.487 & 1.486 \\
\hline $\mathrm{Cv}(\%)$ & & 14.47 & 18.83 & 15.53 & 24.76 & 6.04 \\
\hline
\end{tabular}

ns: non significant, $*$ : significant at $\mathrm{p} \leq 0.05, * *$ : significant at $\mathrm{p} \leq 0.01$

Means comparison of cluster weight, cluster length and yield of grape by Duncan's multiple range test showed that application of all fertilizer treatments increased these characteristics compared to the control. Spray of iron sulfate at concentration of $5000 \mathrm{mg} / \mathrm{L}$ had the highest effect on increasing the mean weight of cluster, while control treatment had the lowest effect on the trait.

Means comparison of the iron concentration showed that treatment of iron sulfate at concentration of $5000 \mathrm{mg} / \mathrm{L}$ with an increase of $933 \mathrm{mg} / \mathrm{kg}$ dry weight of grape leaf in iron content in the second year of the experiment was placed in class A, and the rest of the treatments were placed in class B (Fig. 2). In soil of this experiment, lime rate of soils is high, a problem that prevents the absorption of most elements, including iron. When there is a problem with the absorption of the plant's required elements, the deficiency of these elements causes the appearance of elements deficiency symptoms in the plant, leading to the reduction of photosynthesis and plant yield. When plant is planted in calcareous soils, high rate of lime is either a barrier to the absorption of elements or, because of the high $\mathrm{pH}$ of the plant tissue, makes the elements unavailable for the plant.

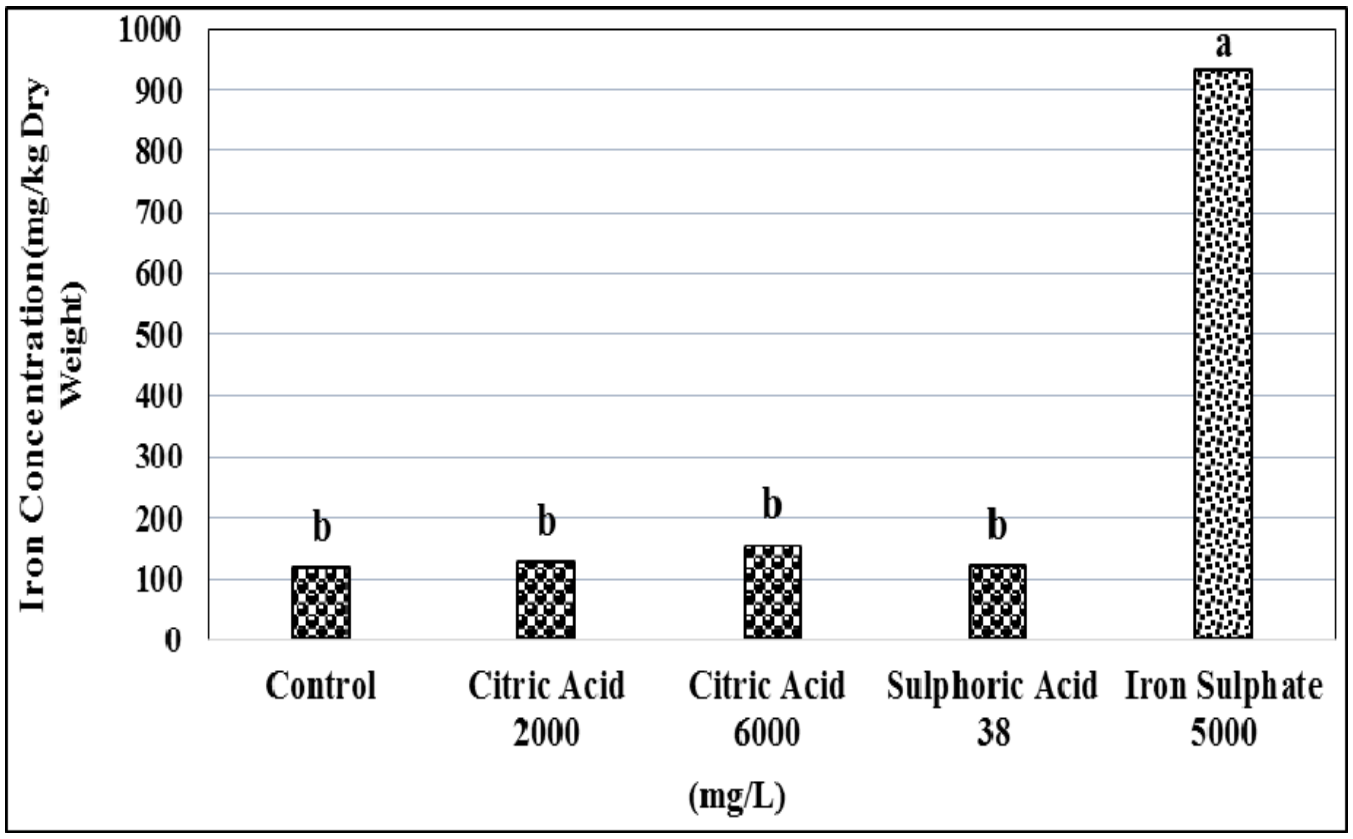

Figure 2. The effect of different treatments on leaf iron concentration in the second year

\subsection{Compound analysis:}

The results of compound analysis of variance of the data for two years showed that the effects of fertilizer treatments and the interaction between years and fertilizer treatments on yield, cluster weight, cluster length and percentage of TSS were not significant. Analysis of the variance of leaves iron concentration for two years showed that the effect of fertilizer treatments on leaf iron content was significant at $1 \%$ probability level ( $\mathrm{p} \leq 0.01$ ), while the interaction between years and fertilizer treatments on leaf iron concentration was significant at $5 \%$ probability level $(\mathrm{p} \leq 0.05$ ) (Table 3 ). 
Table 3. Compound variance analysis of yield, weight and length of cluster, iron concentration and soluble solids content (TSS) of fruit

\begin{tabular}{ccccccc}
\hline & & \multicolumn{5}{c}{ Mean squares } \\
\cline { 3 - 7 } Sources of variation & DF & Yield & $\begin{array}{c}\text { Cluster } \\
\text { weight }\end{array}$ & $\begin{array}{c}\text { Cluster } \\
\text { length }\end{array}$ & $\begin{array}{c}\text { Iron } \\
\text { concentration }\end{array}$ & TSS \\
\hline Replicate & 1 & $22.726^{\mathrm{ns}}$ & $17139.6^{\mathrm{ns}}$ & $57.840^{\mathrm{ns}}$ & $514677.278^{* *}$ & $2.601^{\mathrm{ns}}$ \\
Error & 6 & 53.448 & 3179.267 & 3.403 & 5837.009 & 3.105 \\
Fertilizer treatment & 4 & $31.744^{\mathrm{ns}}$ & $5099.463^{\mathrm{ns}}$ & $0.355^{\text {ns }}$ & $1416966.395^{* *}$ & $0.778^{\text {ns }}$ \\
Fertilizer * year & 4 & $9.579^{\text {ns }}$ & $1104.037^{\text {ns }}$ & $5.272^{\text {ns }}$ & $33966.192^{*}$ & $0.933^{\text {ns }}$ \\
Error & 24 & 17.609 & 2055.683 & 5.999 & 9105.088 & 1.248 \\
\hline $\operatorname{Cv}(\%)$ & & 18.56 & 16.56 & 12.76 & 23.63 & 5.47 \\
\hline
\end{tabular}

ns: non significant, $*$ : significant at $\mathrm{p} \leq 0.05, * *$ : significant at $\mathrm{p} \leq 0.01$

Means comparison of yield, cluster weight, cluster length and TSS showed that although fertilizer treatments had no significant effect on these characteristics, application of these treatments increased the characteristics compared with the control.

Means comparison of iron concentration in grape leaf showed that iron sulfate spraying at concentration of $5000 \mathrm{mg} / \mathrm{L}$ significantly increased the leaf iron content by $1156 \mathrm{mg} / \mathrm{kg}$ dry weight compared with control and other treatments. Iron sulfate treatment at $5000 \mathrm{mg} / \mathrm{L}$ was placed in class A and the rest of the treatments were placed in class B (Fig. 3). Considering the supply of iron as spray solution and its rapid absorption by leaves, increase of iron concentration seems reasonable. It is not unexpected that in calcareous soils, spraying of acidic fertilizers such as iron sulfate increases the iron absorption efficiency and turns it into available form. The results of previous researches on various products confirm this conclusion.

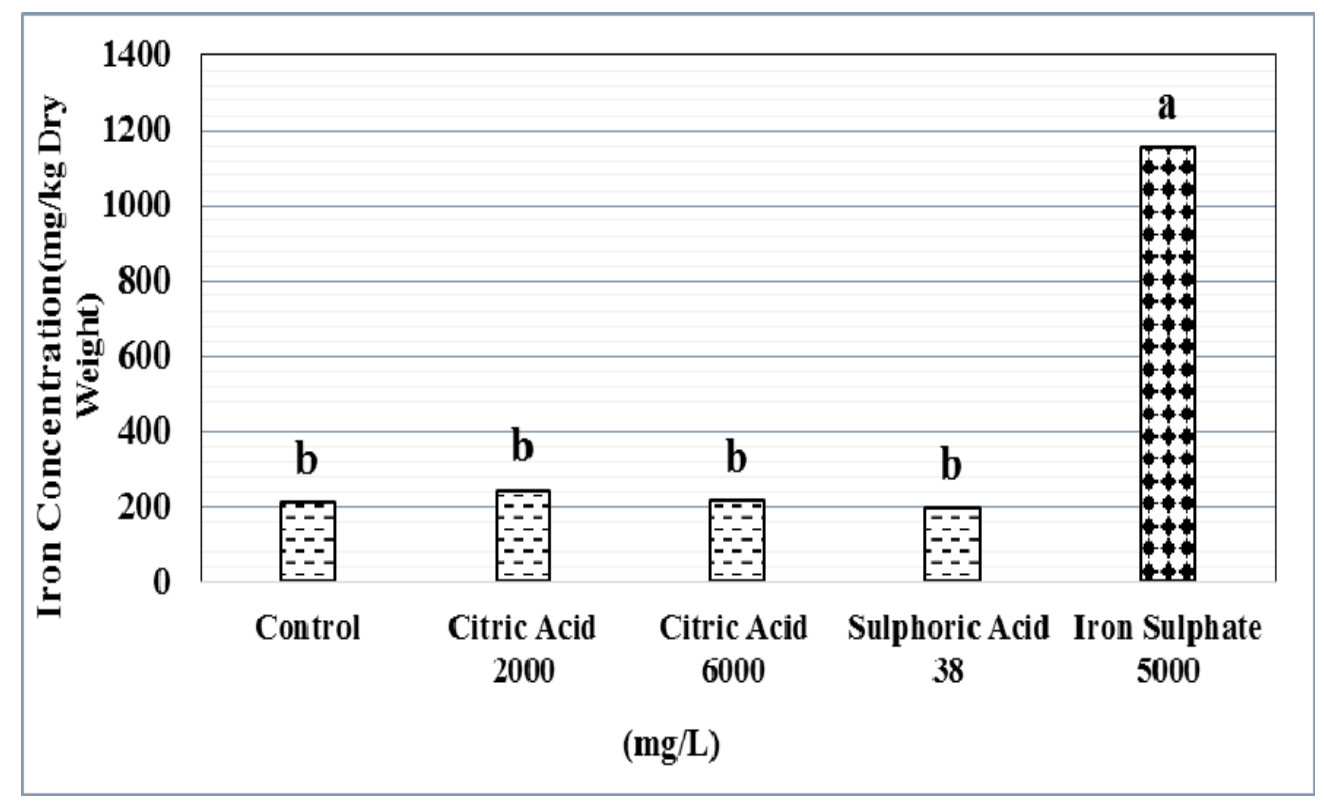

Figure 3. Effect of different treatments on the average iron concentration in two consecutive years

It has been reported in pea (Pisum sativum) that spray of sulfuric acid $(0.1 \%)$ and iron $(0.2 \%)$ resulted in $33.47 \%$ and $29.92 \%$ increases in chlorophyll content (Van den Driessche, 1978). Since using high amounts of iron is effective in preventing leaf chlorosis, much of the iron used in plants is in unavailable and nontransferable form, which cannot be used in plant physiological processes (Colgrove and Roberts, 1956; Sahu et al., 1987). Therefore, the use of acid fertilizers in alkaline soils reduces the $\mathrm{pH}$ of leaves apoplast and converts the iron into a form that can be used in grape leaves, thus improving the yellowing between the veins.

It was reported in another study on pea (Pisum sativum) that sulfuric acid $(0.1 \%)$ and iron $(0.2 \%)$ increased chlorophyll content by $33.47 \%$ and $29.92 \%$, respectively (Van den Driessche, 1978). 


\section{Discussion:}

In southwest of Iran, high rate of lime (about 60 percent) is a problem which prevents the absorption of most elements, in particular iron. When plant cannot absorb its required elements, deficiency of these elements appears as symptoms of deficiency, which reduce the photosynthesis, plant yield, and finally the biomass of the whole plant. High rate of lime in calcareous soils is either a barrier to the absorption of elements by plants or makes the elements unavailable for the plant after absorption, because of the high $\mathrm{pH}$ of the plant tissue. In this experiment, iron sulfate at $5000 \mathrm{mg} / \mathrm{L}$ for two consecutive years increased the amount of leaf iron. One of the reasons for increasing the amount of leaf iron is that the acidity of the fertilizer reduced the $\mathrm{pH}$ of the leaf and increased the amount of leaf iron. Furthermore, iron sulfate, which itself contains iron, increased the amount of leaf iron. Other possible explanation for iron increase is that spray of iron sulfate in calcareous soils instead of its soil application increased the amount of leaf iron. In general, foliar application of iron sulfate at concentration of $5000 \mathrm{mg} / \mathrm{L}$ is recommended to improve iron chlorosis and increase the yield in calcareous soils.

\section{References:}

[1] Bienfait, H.F., Scheffers, M.R., 1992. Some properties of ferric citrate relevant to the nutrition of plants. Plant Soil. 143, 141-144.

[2] Borg, S., Brinch-Pedersen, H., Tauris, B., Holm, P.B., 2009. Iron transport, deposition and bioavailability in the wheat and barley grain. Plant Soil. $325,15-24$

[3] Brown, J.C., 1961. Iron chlorosis in plants. Adv. Agron. 13, 329-369.

[4] Cain, T.C., 1952. A comparison of ammonium and nitrate nitrogen for blueberries. Am. Soc. Hortic. Sci. 59, 161-6.

[5] Carter, M.R., 1980. Association of cation and organic anion accumulation with iron chlorosis of Scots pine on prairie soils. Plant Soil. 56, 293-300.

[6] Chakeralhosseini, M.R., 2000. Effect of nitrogen, boron and zinc solutions on quantitative and qualitative characteristics of grape juice in Kohgiluyeh and Boyerahmad Province - Final report of Kohgiluyeh and Boyerhmad soil and water research Department.

[7] Chen, Y., Barak, P., 1982. Iron nutrition of plants in calcareous soils. Adv. Agron. 35, 217-240.

[8] Colgrove, M.S., Roberts, A.N., 1956. Growth of Azalea as influenced by ammonium and nitrate nitrogen. Am. Soc. Hortic. Sci. 68, $522-36$.

[9] Goodarzi, K., 1999. Determining the balanced limit of nutrients in grape by Dris Method in Kohgiluyeh and Boyerahmad Province Final Report of Kohgiluyeh and Boyerahmad Soil and Water Research Department.

[10] Jozedaemi1, E., Golchin, A., Bibalani, G.H., 2014. The Effect of Soil and Foliar Fertilization with Iron on Yield and Leaf Chemical Composition of Four Spotted Bean Cultivars in a Calcareous Soil. Greener Journal of Biological Sciences. Vol. 4(4), pp. 116-127.

[11] Kirkby, E.A., Mengel, K., 1967. Ionic balance in different tissues of the tomato plant in relation to nitrate, urea or ammonium nutrition. Plant Physiol. 42, 6-14.

[12] Kolesch, H., Hofner, W., Oktay, M., 1984. Effect of iron chlorosis inducing factors on the cytoplasm of sunflower. Plant Soil. 82, 215221.

[13] Kolesch, H., Hofner, W., Schaller, K., 1987. Effects of bicarbonate and phosphate on iron chlorosis of grape with special regard to the susceptibility of two rootstocks. Plant Nut. 10(2), 231-249.

[14] Machold, O., 1967. Investigation on metabolically defect tomato mutants. III Effect of ammonium and nitrate nitrogen on the chlorophyll content -flora, Abt. 157, 536-51.

[15] Malakouti, M.J., Tabatabaei, S., 1999. Proper nutrition of fruit trees. Agriculture Education Publication. P. 266.

[16] Mengel, K., Malissiovas, N., 1982. Light dependent proton excretion by roots of entire vine plants. Pflanzenerahrung Bodenkd. 145, 261-2.

[17] Mengel, K., Breniniger, M., Bubl, W., 1984. Bicarbonate, the most important factor inducing iron chlorosis in grape on calcareous soils. Plant Soil. 81, 333-344.

[18] Mengal, K., Geurtzen, G., 1988. Relation between iron chlorosis and alkalinity in Zea mays. Physiol. Plant. 72, 460-65.

[19] Mengal, K., Planker, R., Hoffmann, B., 1994. Relationship between leaf apoplast pH and iron chlorosis of sunflower. Plant nutrition. 17(6), 1053-65.

[20] Pfeiffer, W.H., McClafferty, B., 2007. Biofortification: breeding micronutrient-dense crops. In: Kang MS, Priyadarshan PM, editors. Breeding major food staples. New York: Blackwell Science; PP. 61-91.

[21] Sahu, M.P., Sharma, D.D., Jain, G.L., Singh, H.G., 1987. Effects of growth substances, sequestrene 138-Fe and sulphuric acid on iron chlorosis of garden peas. Hort. Sci. 62(3), 391-394.

[22] Salardini, AS., 2009. Soil Fertility. Tehran University Press. P. 440.

[23] Tagliavini, M., Bassi, D., Marangoni, B., 1993. Growth and mineral nutrition of pear rootstocks. Sci. Hortic. 45, 280-283.

[24] Tagliavini, M., Scudellari, D., Marangoni, B., Toselli, M., 1995. Acid-spray regreening of kiwifruit leaves affected by lime-induced iron chlorosis. Plant soil. PP. 191-195.

[25] Van den Driessche, R., 1978. Response of Douglas Fir seedling to nitrate and amonium nitrogen source at different levels of $\mathrm{pH}$ and iron supply. Plant Soil. 49, 607-23. 